\title{
What's in a drug name?
}

In DeCEMBER 2011, THE US Food AND DrUg AdMINISTRATION (FDA) reported that at least one serious injury occurred when Durasal (salicylic acid, 26\%), a topical wart remover, was dispensed to a patient following eye surgery instead of Durezol (difluprednate), a topical corticosteroid eye drop. Prior to this incident, the FDA issued a notice that several other cases of confusion between Durezol and Durasal had been reported. ${ }^{1}$

Instances of drug confusion due to look-alike or soundalike drug names continue to be reported in Canada as well. For example, in November 2011, Health Canada released a notice regarding potential confusion between the anticoagulant Pradax (dabigatran) and the antiplatelet drug Plavix (clopidogrel). In 2011 alone, there were 5 reported Canadian cases involving mix-ups between the 2 drugs, with at least one case of confusion resulting in patient harm. ${ }^{2}$

While numerous advisories on drug name confusion have been released to date, it is widely acknowledged that medication mix-ups are significantly underreported. ${ }^{3}$ Furthermore, Health Canada notices only take into account postmarket reports of confusion and, as such, do not capture the premarket cases of potential confusion identified during the drug submission and approval processes.

In addition to patient harm arising from medication errors due to similar drug names, cases of drug name confusion can have significant pre- and postmarket implications for drug manufacturers, such as delays in drug submission approval, potentially significant costs associated with renaming drug products (e.g., relabelling, repackaging, etc.) and a suspension of drug sales by Health Canada. ${ }^{4}$

When manufacturers make a drug product submission, Health Canada undertakes to identify potential instances of drug confusion by-among other methods-searching for similar proprietary and nonproprietary names, orthographic or phonetic computer analyses, verbal and handwritten prescription testing studies, reviews of medication error literature and/or systematic assessments of the proposed name, taking into account contributing factors (i.e., dosage form or route of administration) and process flow (i.e., who purchases the drug, where it is stored, where it is used). ${ }^{5}$
Drug manufacturers may submit a maximum of 2 prioritized alternative drug names with a drug submission. In the event that the Health Products and Food Branch (HPFB) of Health Canada identifies a potentially confusing name during the drug submission review process and disallows the use of the confusing name, the HPFB will then consider the alternative names submitted by the sponsor. ${ }^{5}$

Medication errors due to drug name confusion may occur at various stages between the time a drug is prescribed and administered. ${ }^{6,7}$ For example, in 2004, Janssen-Ortho and Aventis Pharma released a joint safety bulletin for health care professionals regarding mix-ups between the Alzheimer's medication Reminyl (galantamine hydrobromide) and the diabetes medication Amaryl (glimepiride). The bulletin reported that errors were caused by prescriptions that were incorrectly written, interpreted, labelled or dispensed due to the similarity between the 2 medication names. In addition to having similar names, Reminyl and Amaryl have an overlapping strength (4 mg), have an overlapping dosage form (tablets) and may be stored or shelved in close proximity due to their generic names. Notably, the medications were mixed up despite the fact that Reminyl and Amaryl tablets are different shapes (circular and oblong, respectively) and are imprinted with distinct identifiers (i.e., JANSSEN and AMARYL, respectively). ${ }^{7}$

In order to mitigate the potential problems due to drug name confusion, including medication errors, manufacturers should consider the following naming suggestions:

1. Limit proprietary drug names to one word and avoid qualifications by letters or numbers;

2. Ensure that brand names and generic names for drug products that contain different medicinal ingredients are easily distinguishable;

3. Use caution when adding a prefix or suffix to modify the name of another drug in order to indicate a product line extension (Sponsors should be prepared to furnish Health Canada with a rationale as to why it is unlikely that the proposed drug name will give rise to safety or efficacy concerns.); and/or

4. Incorporate a prefix that represents the manufacturer's name into the drug name. 
In addition, the Collaborating Centre for Patient Safety Solutions of the World Health Organization suggests that medication labels should:

- Include the proprietary and nonproprietary names of the medication, with the nonproprietary name in proximity to and in a larger font size than the proprietary name.

- Use boldface and colour differences to reduce potential confusion.

- Emphasize drug name differences by using methods such as "tall man" lettering (the practice of writing part of a drug's name in uppercase letters to help distinguish sound-alike, look-alike drugs from one another). ${ }^{8-10}$

Other suggestions include:

- Use distinguishing colours and shapes for medication packaging (i.e., bottles, tubes, etc.). ${ }^{11}$

- Use distinguishing colours and shapes for the dosage forms themselves (e.g., tablets), if applicable.

- Make indications and dosage strengths more prominent on the package labelling.

- Spell out medication names phonetically in brackets to reduce the chances of confusion due to mispronunciation.

Drug manufacturers should take note of the above suggestions in order to reduce the likelihood of pre- and/or postmarket regulatory complications with their preferred drug name.

From Fasken Martineau DuMoulin LLP, Toronto, Ontario.Contact: rcheung@fasken.com.

\section{References}

1. US Food and Drug Administration. FDA alerts pharmacists and health care professionals to potential for injury when dispensing the similar-sounding drugs Durezol and Durasal. Available: www.fda.gov/Drugs/DrugSafety/ucm 285235 .htm (accessed March 20, 2012).
2. Health Canada. Pradax (dabigatran etexilate) and Plavix (clopidogrel bisulfate)-risk of potential patient harm associated with brand name confusion-for health professionals; 2011 Nov 8. Available: www.hc-sc.gc.ca/ dhp-mps/medeff/advisories-avis/prof/_2011/plavix_2_hpc-cps-eng.php (accessed March 20, 2012).

3. Institute for Safe Medication Practices. Frequently asked questions: what is the national medication error rate? What standards are available for benchmarking? Available: www.ismp.org/faq.asp\#Question_1 (accessed March 20, 2012).

4. Health Canada. Release of revised draft guidance document: marketed health product name assessment: look-alike sound-alike (LA/SA) health product names. 2005 Nov 24. Available: www.hc-sc.gc.ca/dhp-mps/brgtherap/proj/ alike-semblable/lasa-pspcs_post_market-comm_guidance-directive_2-eng .php (accessed March 20, 2012).

5. Health Canada. Guidance for industry: drug name review: look-alike, sound-alike (LA/SA) health product names. 2005 Oct 31. Available: www .hc-sc.gc.ca/dhp-mps/brgtherap/applic-demande/guides/drugs-drogues/lasa_ premkt-noms_semblables_precomm-eng.php (accessed March 20, 2012).

6. Health Canada. Important safety information regarding medication errors resulting from confusion between Seroquel and Serzone-5HT2-Astra Zeneca and Bristol-Myers Squibb. 2002 Oct 31. Available: www.hc-sc.gc.ca/ dhp-mps/medeff/advisories-avis/prof/_2002/seroquel-serzone_hpc-cps-eng .php (accessed March 20, 2012).

7. Health Canada. Medication errors involving Reminyl and AmarylJanssen-Ortho Inc. and Aventis Pharma Inc. 2004 Dec 17. Available: www .hc-sc.gc.ca/dhp-mps/medeff/advisories-avis/prof/_2004/reminyl_amaryl_ ltp-lp-eng.php (accessed March 20, 2012).

8. WHO Collaborating Centre for Patient Safety Solutions. Look-alike, soundalike medication names. Geneva (Switzerland): World Health Organization; 2007. Available: www.ccforpatientsafety.org/common/pdfs/fpdf/Presskit/PSSolution1.pdf (accessed March 20, 2012).

9. Look-alike/sound-alike drug names: can we do better in Canada? ISMP Canada Saf Bull 2004;4(2). Available: http://ismp-canada.org/download/ safetyBulletins/ISMPCSB2004-02DrugNames.pdf (accessed March 20, 2012). 10. Gabriele S. The role of typography in differentiating look-alike/sound-alike drug names. Healthc Q 2006;9(Spec No):88-95.

11. Health Canada. Maalox Multi Action (bismuth subsalicylate)—confusion with other Maalox liquid products-for health professionals. 2010 May 12 . Available: www.hc-sc.gc.ca/dhp-mps/medeff/advisories-avis/prof/_2010/maalox_ hpc-cps-eng.php (accessed March 20, 2012). 